\title{
DIVERSIFICAÇÃO DO TREINAMENTO EM ORGANIZAÇÕES CONTÁBEIS: UMA ANÁLISE EMPÍRICA UTILIZANDO MODELOS DE CONTAGEM
}

\section{DIVERSIFICATION OF TRAINING IN ACCOUNTING FIRMS: AN EMPIRICAL ANALYSIS USING COUNTING MODELS}

\section{DIVERSIFICACIÓN DEL ENTRENAMIENTO EN ORGANIZACIONES CONT- ABLES: UN ANÁLISIS EMPÍRICO UTILIZANDO MODELOS DE CONTAJE}

\section{FREDERICO A. DE CARVALHO}

Economista, UFRJ. Estatístico, ENCE. Doutor em Economia, UCL, Louvain, Bélgica. Professor Associado I, FACC - UFRJ. Endereço:Rua Dona Maria, 303, Aninha Moura Javary 26900-000, Miguel Pereira-RJ. E-mail: fdecarv@gmail.com

\section{MARCELO RESENDE}

Mestre em Economia, PUC-RJ. Doutor em Economia, Oxford. Pós-doutor, European University Institute, Florença. Professor Associado III, IE - UFRJ. Endereço: Instituto de Economia - UFRJ, Avenida Pasteur, 250, Praia Vermelha, 22290-240 - Rio de Janeiro-RJ.

Email: mresende@ie.ufrj.br

\section{FRANCISCO JOSÉ DOS SANTOS ALVES}

Mestre em Contabilidade, UERJ. Doutor em Contabilidade e Controladoria, USP. Professor Adjunto e Coordenador do Mestrado em Ciências Contábeis, FAF - UERJ. End: Programa de Pós-graduação em Ciências Contábeis - UERJ. Endereço: Rua São Francisco Xavier, 524, $9^{\circ}$ andar, Bloco E, Maracanã, 20550-013 - Rio de Janeiro-RJ. E-mail:

\section{MARCELINO JOSÉ JORGE}

Mestre em Economia, Universidade de Brasilia. Doutor em Engenharia de Produção, COPPE/UFRJ. Membro da equipe docente do Programa de Pós-Graduação Stricto Sensu do Instituto de Pesquisa Clínica Evandro Chagas/FIOCRUZ. Endereço: Avenida Padre Natuzzi, 22, São Francisco, 24360-180. E-Mail: 


\section{RESUMO}

Este trabalho tem por objetivo testar hipóteses acerca da influência de características organizacionais sobre a diversificação das atividades de treinamento eventualmente praticadas por empresas prestadoras de serviços profissionais contábeis. Como suporte empírico, foi utilizada uma amostra de conveniência gerada no estado do Rio de Janeiro a partir da resposta de 531 organizações a um questionário postal contendo 38 questões de diversos tipos. Dessas questões, foram exploradas as mais diretamente relacionadas à oferta de oportunidades de treinamento aos empregados. Utilizando a especificação e estimação de dois modelos de regressão múltipla, foi possível encontrar que a diversidade do treinamento está positivamente associada ao número de empregados, à atividade inovadora, à diversidade dos serviços ofertados e a duas variáveis representando atenção ao mercado, mas não se vincula à idade nem à localização da organização. Esses resultados interessam não somente à programação de treinamento pelos gestores internos, ajudando-os a antecipar demandas ou aproveitar oportunidades, mas também a organizações que forneçam tais programas, tanto privadas quanto públicas, incluindo conselhos profissionais.

Palavras-chave: Serviços Profissionais; Organizações Contábeis; Treinamento; Modelos de Contagem.

\section{ABSTRACT}

This paper aims to test hypotheses on the influence of organizational characteristics on the diversification of training activities occasionally practiced by those businesses which supply professional accounting services. As empirical support, a convenient sample was used, generated in the state of Rio de Janeiro through the answers of 531 organizations to a postal questionnaire consisting of 38 questions of varying types. Of these questions, those most closely related to the offer of training opportunities to employees were explored. Utilizing the specification and estimation of two multiple regression models, it was possible to identify that the diversity of training is positively associated with the number of employees, with innovative activity, with the diversity of services being offered, and with another two variables representing market awareness, but not with the age nor location of the organization. These results are of interest not only for the programming of training activities by internal managers, assisting them in anticipating demands or to taking advantage of opportunities, but also to organizations, both public and private, that supply such programs, including professional councils.

Keywords: Professional Services; Accounting Firms; Training; Counting Models. 


\section{repec}

Diversificação do Treinamento em Organizações Contábeis: Uma Análise Empírica Utilizando Modelos de Contagem

\section{RESUMEN}

Este trabajo tiene por objetivo testar hipótesis acerca de la influencia de características de organización sobre la diversificación de las actividades de entrenamiento eventualmente practicadas por la empresa prestadora de servicios profesionales contables. Como soporte empírico fue utilizada una muestra de conveniencia, generada en el estado de Rio de Janeiro a partir de la respuesta de 531 organizaciones a un cuestionario postal conteniendo 38 cuestiones de diversos tipos. De estas cuestiones, fueron explotadas las más directamente relacionadas a la oferta de oportunidades de entrenamiento a los empleados. Utilizando la especificación y estimación de dos modelos de regresión múltiple, fue posible encontrar que la diversidad del entrenamiento está positivamente asociada al número de empleados, a la actividad innovadora, a la diversidad de los servicios ofertados y a dos variables representando atención al mercado, pero no a la edad, ni a la localización de la organización. Esos resultados interesan no solamente a la programación de entrenamiento por los gestores internos, ayudándolos a anticipar demandas o aprovechar oportunidades, sino también a organizaciones que proporcionen tales programas, tanto privadas, como públicas, incluyendo consejos profesionales.

Palabras clave: Servicios Profesionales; Organizaciones Contables; Entrenamiento; Modelos de Contaje.

\section{INTRODUÇÃO}

O pressuposto básico desta pesquisa estipula que a diferenciação e o sucesso das organizações prestadoras de serviços estão associados ao desempenho e à capacitação profissional dos seus funcionários. Nesse contexto, capacitação significa dotar os funcionários das habilidades, das ferramentas e dos recursos de que necessitam para utilizar seu próprio arbítrio profissional com confiança e eficácia (LOVELOCK e WRIGHT, 2004, p. 396). Esse pressuposto encontra amplo suporte empírico na literatura internacional consultada.

Quando se trata de serviços profissionais, tais como os serviços médicos ou os contábeis, a qualidade da mão de obra é particularmente importante, pois diversos tipos de saberes, além dos conhecimentos técnicos das respectivas áreas, são requeridos para atender os clientes. Por exemplo, na área contábil, recentemente têm crescido em importância os conhecimentos especializados na área de informática, que se tornaram parte integrante do conjunto de competências requeridas de auditores e contadores. Sendo assim, é de esperar que a decisão de oferecer treinamento por parte de uma organização contábil deva contemplar um leque diversificado de tipos de treinamento profissional e técnico, que é precisamente o tema deste trabalho. 
O objetivo da pesquisa é examinar quantitativamente aspectos da oferta de treinamento no ambiente de serviços contábeis, aproveitando dados primários relativos a sociedades e escritórios contábeis localizados no Estado do Rio de Janeiro e investigando especificamente a existência de associação entre aquela oferta e algumas características organizacionais selecionadas, tais como tamanho ou o local em que está sediada a organização prestadora.

O texto está organizado em quatro seções que se seguem a esta introdução. $\mathrm{Na}$ primeira seção, a resenha da literatura indica a fundamentação teórica do estudo. A metodologia adotada aparece na segunda seção, enquanto na terceira seção são apresentados os resultados do estudo. Comentários conclusivos, na quarta seção, completam o texto.

\section{REFERENCIAL TEÓRICO}

Nesta seção expõem-se os fundamentos teóricos da pesquisa. As duas subseções abordam a gestão de pessoas. A primeira subseção trata do caso geral das prestadoras de serviços profissionais, entre os quais se incluem os serviços contábeis, revistos na subseção seguinte.

\subsection{Gestão de pessoas em empresas prestadoras de serviços}

De acordo com Lovelock e Wright (2004, p. 391), em empresas de serviços bem sucedidas as pessoas são vistas mais como recurso a ser desenvolvido do que como custo a ser minimizado. Para Bateson e Hoffman (2001, p. 175), que consideram os prestadores dos serviços como o lado humano da organização, políticas de recursos humanos demonstram ter uma relação direta com os resultados vivenciados pelos clientes. Apesar disso, muitas empresas ainda cultivam um modelo de gerenciamento de recursos humanos baseado em velhos modelos de minimização de custos. O gestor de hoje procura maneiras de liberar-se desses antigos modelos.

Políticas de gerenciamento de recursos humanos também ajudam a criar comprometimento dentro da organização. Quando o comprometimento é intenso, os funcionários mostram interesse efetivo em cumprir bem qualquer atividade relacionada ao trabalho. Em particular, eles se envolvem diretamente no processo de prestação do serviço, preocupandose quanto às opiniões dos clientes (BATESON e HOFFMAN, 2001, p. 176). Na visão desses autores, empresas que usam estrategicamente políticas de gestão de recursos humanos veem o treinamento como uma via para melhor desempenho competitivo (p. 178-179).

Além de educar e motivar seus funcionários, as sessões de treinamento estimulam o funcionário a assumir compromisso com a empresa. Quando isso ocorre, os funcionários permanecem leais e tornam-se fonte para indicação de novos funcionários, fornecendo referências sobre amigos ou pessoas de suas relações. Essas referências não somente re- 


\section{repec}

Diversificação do Treinamento em Organizações Contábeis: Uma Análise Empírica Utilizando Modelos de Contagem

duzem os custos de recrutamento, mas também aumentam significativamente a qualidade do candidato.

Nas organizações contábeis necessita-se, para atender os clientes, de diversos tipos de saberes profissionais, não necessariamente relacionados às teorias ou às técnicas contábeis, tais como os de recepcionistas, arquivistas, secretárias, digitadores, mensageiros e, mais recentemente, especialistas em informática operacional, que cuidam do bom andamento dos equipamentos, dos aplicativos e outros programas, da rede interna ou da Internet, entre outros (THOMÉ, 2001, p. 23). A busca da qualidade no atendimento leva a supor, então, que as necessidades de treinamento nessas organizações sejam amplamente diversificadas.

A fim de construir uma equipe orientada para clientes e com uma mentalidade de serviços, uma organização deve (1) contratar as pessoas certas, (2) desenvolvê-las para que forneçam serviços de qualidade, (3) fornecer os sistemas de apoio necessários, e (4) reter as melhores pessoas (ZEITHAML e BITNER, 2003, p. 266). Empresas bem sucedidas investem intensamente em treinamento e asseguram-se de que o programa atenda às metas e às estratégias do negócio (Ibid., p. 271). Além disso, uma empresa com empenho estratégico no desenvolvimento das habilidades e dos conhecimentos de seus empregados ganha reputação por investir nas pessoas e obtém os devidos benefícios.

Passando da prescrição à reflexão teórica, pode-se dizer que, na literatura resenhada, a contribuição proeminente é atribuída a Becker (1964), posteriormente retomada, em termos empíricos, por diversos autores (BLACK; BRETT; WANG, 1999 e TURCOTTE; LEONARD; MONTMARQUETTE, 2003). Estes últimos invocam a chamada "teoria do capital humano" para distinguir os fatores determinantes da oferta de treinamento pela empresa em "estruturais" (que incluem tamanho, idade, setor de atividade e localização, entre outras), "competitivas e estratégicas" (que incluem inovação, tecnologia e aspectos concorrenciais, entre outras) e "relacionadas ao empregado" (workforce characteristics), (p. 31-35).

O tamanho da empresa, medido em número de empregados ou em faturamento, é certamente uma das variáveis mais citadas na literatura sobre treinamento, independentemente de filiação teórica (GOETZ; MORROW; MCELROY, 1991, HENDRY, 1991, HOLTMANN; IDSON, 1991, SHIELDS, 1998, WESTHEAD, 1998, BLACK; BRETT; WANG, 1999; REID; HARRIS, 2002). Outras considerações teóricas argumentam que a decisão de oferecer treinamento pode ser parte de uma estratégia empresarial mais ampla, voltada à busca de competitividade (por exemplo, MYTZEK-ZÜHLKE; NITSCHE, 2006). Seguindo essa abordagem mais "gerencial", foram destacadas a pressão concorrencial (SMITH et al., 1995) ou a estratégia relativa a produtos / mercados (SMITH et al., 1995, KEEP; MAYHEW, 1996). Para estes últimos, por exemplo, competir com base em produtos ou serviços padronizados e de baixo custo deverá criar uma reduzida demanda por treinamento (p. 327). Todas essas fontes sustentam a escolha de variáveis expostas mais adiante. 


\subsection{Treinamento em empresas prestadoras de serviços profissionais contábeis}

No que diz respeito ao treinamento de prestadores de serviços contábeis, a literatura, tanto nacional quanto internacional, não tem dedicado muito espaço ao tema. Isto é surpreendente na medida em que, já no início do século XX, Luman (1911) defendeu a importância do treinamento em Contabilidade. Sob uma perspectiva holística, o autor alertou para a necessidade de aperfeiçoamento do contador no idioma e na matemática. Ele também defendia a ideia de que ao se intensificar a preparação, alargam-se as portas da oportunidade.

Em meados do século passado, Archerd (1951) abordou questões relacionadas ao treinamento de novos contadores. Logo depois, Kurlander e Battista (1960) discutiram especificamente programas de treinamento formal e informal em organizações contábeis, enquanto que Pitts (1962) discorreu sobre diversos aspectos de programas de treinamento voltados para trainees.

Mais recentemente, a literatura tem produzido trabalhos acerca de várias questões envolvendo os contadores e tratando de temas tais como motivação, profissionalismo, estresse e sobrecarga de trabalho, entre outros. Por exemplo, analisando a sobrecarga de trabalho em períodos de alta demanda por serviços contábeis, Sweeney e Summers (2002) relatam que a carga de trabalho escalada durante o período de pico (busy season) do profissional de Contabilidade é um fator grandemente responsável pela exaustão e estresse do funcionário. Esses autores empregaram um modelo de equações estruturais para examinar o impacto da carga de trabalho durante a alta temporada sobre a exaustão do profissional.

No caso brasileiro, Almeida (2003, p. 156-157), ao abordar aspectos relacionados ao planejamento de auditoria, constatou que a maioria das empresas encerra seu exercício social em dezembro de cada ano. Isso faz com que haja concentração e acúmulo de serviços de auditoria externa nos três meses seguintes a dezembro (busy season), enquanto nos outros meses do ano (abril a dezembro), essas empresas passam por certa ociosidade. Para contornar esse problema, os auditores externos executam, sempre que possível, maior volume de serviços de auditoria nas visitas preliminares. Mesmo assim, nos períodos de pico podem surgir dificuldades de gestão de pessoas em ambiente de sobrecarga, especialmente se não possuírem treinamento adequado.

Sob o ponto de vista empírico, no caso brasileiro só foi possível identificar uma pesquisa abordando a questão do treinamento em organizações contábeis (CFC, 1996). O objetivo geral dessa pesquisa foi definir o perfil sócio-econômico e cultural do contabilista brasileiro, bem como obter indicativos para orientar a atuação do Conselho Federal de Contabilidade (CFC) como autarquia federal. Não foi possível localizar outras referências sobre o tema do treinamento em organizações contábeis, apesar de muitos conselhos regionais oferecerem cursos aos profissionais registrados. Nessa pesquisa do CFC, o campo de ati- 
vidades do contabilista brasileiro estava, então, delimitado em função do porte da empresa, da natureza jurídica e do ramo de atividade, bem como das condições de trabalho e da complexidade da legislação.

Quando se perguntou acerca do interesse em participar de treinamento, a maioria dos respondentes $(71 \%)$ demonstrou desejo de participar desses programas, não obstante o fato de as empresas para as quais trabalhavam terem demonstrado elevado grau de satisfação com seus serviços. Ao abordar quais as áreas de interesse para fins de treinamento, a pesquisa verificou que os contabilistas deram preferência a programas que capacitam para atendimento ao mercado: é o caso dos treinamentos sobre imposto de renda (pessoa física e jurídica), informática para a área contábil, legislação tributária, legislação fiscal, Contabilidade de Custos, auditoria e Contabilidade Pública, nessa ordem.

Além disso, os dados indicaram que os contabilistas mais jovens participaram, em percentual elevado, dos seminários e cursos de aperfeiçoamento, enquanto os respondentes de faixas etárias mais elevadas participaram, em maior expressão, dos congressos e convenções. Acompanhando essa tendência, $85 \%$ dos jovens, na faixa de 18 a 25 anos, desejavam participar de algum treinamento, percentual que passa a ser decrescente nas faixas etárias mais elevadas, chegando a apenas $38 \%$ na faixa de idade superior a 55 anos

\section{METODOLOGIA}

Nesta seção descrevem-se os passos metodológicos adotados no desenvolvimento da pesquisa. São discutidas, nesta ordem, a questão e a hipótese da pesquisa; o universo e a amostra; as variáveis utilizadas e a coleta de dados; o tratamento estatístico adotado; e as limitações do estudo.

\subsection{Questão e hipóteses da pesquisa}

Esta pesquisa investiga se características organizacionais selecionadas influenciam ações relacionadas ao treinamento de pessoal. As fontes teóricas que sustentam a escolha de variáveis e de hipóteses foram resenhadas na segunda seção. A questão a ser investigada pode ser sintetizada na seguinte pergunta de pesquisa: As características organizacionais influenciam a oferta de treinamento?

Para responder essa pergunta, é proposta e testada uma hipótese composta que expressa possíveis associações entre, de um lado, características das organizações contábeis amostradas e, de outro lado, a diversificação de atividades de treinamento, medida pelo número de diferentes tipos de treinamento oferecidos. Mais precisamente, segundo a hipótese de pesquisa a ser testada, a oferta de treinamento é diretamente influenciada por características organizacionais, tais como natureza, tamanho, localização, idade, introdu- 
ção de novos serviços ou o leque de serviços prestados, entre outras. Em termos estatísticos, a hipótese nula associada pode ser escrita como:

$\mathrm{H}_{0}$ : $\quad$ A oferta de treinamento não está associada a características organizacionais tais como natureza, tamanho, localização, idade, leque de serviços, temas analisados e monitoramento da concorrência.

Cinco sub-hipóteses nulas podem ser especificadas a partir da hipótese nula, uma para cada característica que se queira considerar. Por exemplo,

$\mathrm{H}_{0-1}$ : A oferta de treinamento não está associada à natureza da organização contábil;

Vale observar que a oferta de treinamento, nas organizações contábeis pesquisadas, poderia ser representada por duas variáveis dependentes distintas. A primeira, relativa à existência de treinamento na organização, foi levantada, na pesquisa, por intermédio da pergunta: "Esta empresa/escritório oferece treinamento para seus funcionários ou gerentes?". A segunda alternativa seria indicar a diversificação do treinamento através do número de diferentes tipos de treinamento oferecidos aos funcionários e gerentes, obtido pela soma numérica das alternativas dicotômicas ("marcar" = 1 ou "não marcar" = 0) à pergunta: "Que tipos de treinamento os funcionários ou gerentes recebem com maior frequência?"

A primeira definição requer a aplicação de regressão logística e será abordada em outro trabalho. Neste artigo considera-se apenas a segunda alternativa. A operacionalização da variável dependente, na forma aqui adotada, refere-se, pois, ao número de tipos de treinamento, de modo que será mais adequado evitar o uso da estimação por Mínimos Quadrados Ordinários (MQO), que poderia gerar valores negativos ou fracionários, impróprios para a variável dependente.

Uma alternativa aos MQO, bastante difundida para tratar uma variável dependente que assume valores inteiros não negativos, recorre aos chamados modelos de contagem. Dentre tais modelos, uma formulação bastante tradicional (CAMERON e TRIVEDI, 1998) é a do modelo de Poisson, em que a função (condicionada) de probabilidade de y dado x é dada por:

$$
\operatorname{Pr}\left\langle Y_{i}=y_{i} \mid x_{i}\right\rangle=\frac{e^{-\mu_{i}} \mu_{i}^{y_{i}}}{y_{i} !} \quad \text { para } \quad y_{i}=0,1,2 \ldots
$$

O elo com as variáveis explicativas justificadas pela teoria é dado pela equação logarítmica $\ln \left(\mu_{i}\right)=x_{i}^{\prime} \beta$, onde $x^{\prime}$ indica o vetor-linha de características e $\beta$ o vetor-coluna de parâmetros a estimar.

Como se sabe (DIXON e MASSEY, 1969, p. 248), o modelo de contagem de Poisson incorpora, contudo, a hipótese restritiva de que a média é igual à variância (hipótese 


\section{repec}

Diversificação do Treinamento em Organizações Contábeis: Uma Análise Empírica Utilizando Modelos de Contagem

de equidispersão), isto é, $\operatorname{var}(y / x)=E(y / x)=\mu_{\mathrm{I}}=\exp \left(\mathrm{x}_{\mathrm{i}} \beta\right)$. Frequentemente essa hipótese não se verifica em trabalhos aplicados. Assim sendo, é importante implementar testes para superdispersão (overdispersion tests) que contrastam o modelo de Poisson com modelos mais gerais, como é o caso da distribuição Binomial Negativa, segundo a qual $E\langle y \mid x\rangle=\mu_{i}$ e $\operatorname{Var}\langle y \mid x\rangle=\mu_{i}+\alpha \mu_{i}^{2}(2)$.

\subsection{Universo, Amostra e Coleta dos Dados}

Nesta pesquisa usa-se a expressão "organização contábil" com o mesmo significado adotado pelo CFC (CFC, 1999, p. 3), em particular no que se refere ao uso dos termos "sociedade / empresa" ou "escritório". O universo da pesquisa é o conjunto das sociedades e escritórios contábeis regularmente inscritos e ativos no CRC-RJ até outubro de 2002. Uma amostra de conveniência foi obtida do universo, contendo 1.804 sociedades e 1.466 escritórios, num total de 3270 respondentes, representando $95 \%$ e $90 \%$ dos respectivos totais desse universo. Considerando os custos de postagem e resposta, bem como o tempo de reação dos respondentes, esse número foi considerado aceitável, especialmente no que diz respeito à taxa esperada de resposta para este tipo de coleta. A amostra efetiva utilizada nesta pesquisa foi constituída a partir de respostas efetivamente obtidas dos questionários enviados e relacionadas ao tema em discussão.

As variáveis utilizadas para representar os atributos organizacionais são de vários tipos, conforme indica o Quadro 2.1. As variáveis qualitativas, chamadas dummies, são um artifício para permitir a inclusão, no modelo de regressão, de variáveis que, normalmente, não são quantificadas - tais como sexo, religião ou cor - mas que influenciam o comportamento da variável a ser explicada. Por exemplo, uma variável dummy assume valores numéricos para indicar ausência ou presença (ou posse) de um atributo dicotômico. Nesta pesquisa, o uso das variáveis dummies - por exemplo, resposta "não" (0) ou "sim" (1) - possibilitou a operacionalização de várias dicotomias, não somente nos testes de hipóteses como também no cálculo das frequências.

A coleta de dados foi realizada por meio de um questionário autoadministrado, remetido por via postal e apoiado pelo CRC-RJ. O questionário foi dividido em duas partes. A segunda parte, que continha as perguntas propriamente ditas, apresentava 38 questões de diversos tipos, distribuídas em seis páginas, incluindo perguntas fechadas, abertas e semi-abertas. Correspondentemente, houve diversas alternativas de resposta, a saber, dicotômicas (só permitem duas respostas), múltipla escolha com alternativas únicas ou não, escalas de Likert (a pessoa entrevistada indica o quanto concorda ou discorda), escalas de importância (escala variando, p. ex., de "insignificante" até "extremamente importante") e escalas de classificação (que propõem a classificação de algum atributo), além das tradicionais questões destinadas a estabelecer o perfil das organizações e das pessoas respondentes. 
Os questionários foram postados por intermédio do CRC-RJ, em outubro de 2002, em envelope timbrado contendo envelope franqueado para resposta e, ainda, uma carta assinada pelo presidente do CRC-RJ, remetida para os respondentes como atestado da importância da pesquisa. As respostas foram aceitas até dezembro de 2002 e no total foram recebidos 697 questionários, dos quais 695 foram considerados válidos.

\subsection{Tratamento e análise dos dados}

Dos 695 questionários válidos, 531 foram finalmente selecionados para constituir a amostra final, tendo em vista a conveniência de eliminar dados relativos a organizações contábeis que responderam "não ter empregados", "não ter clientes" ou "estar fechada". Do questionário elaborado, foram selecionadas treze perguntas, todas relacionadas à gestão de pessoas.

As tabelas de frequências, as medidas de posição e os testes de hipóteses foram processados com a utilização dos pacotes estatísticos SPSS for Windows - versão 12 e Stata S. E.-versão 9. Os resultados foram analisados em duas fases. No primeiro momento, o perfil dos respondentes foi delineado com base nas frequências relativas e em medidas de posição (médias, medianas e modas). No segundo momento, dada a natureza das variáveis utilizadas, foram estimadas duas equações de regressão linear múltipla para testar a hipótese nula por meio das associações estatisticamente significativas entre as variáveis dependentes e independentes.

\section{Quadro 2.1. Variáveis da Pesquisa}

\begin{tabular}{|c|c|c|c|c|}
\hline Nome & Usada como & Definição & Escopo & $\begin{array}{c}\text { Sinal } \\
\text { esperado }\end{array}$ \\
\hline $\begin{array}{l}\text { Número de tipos } \\
\text { de treinamento }\end{array}$ & $\begin{array}{l}\text { Dependente } \\
\text { numérica }\end{array}$ & $\begin{array}{l}\text { Soma das dummies para "tipos } \\
\text { assinalados" }\end{array}$ & $\begin{array}{l}\text { Diversificação } \\
\text { no treinamento }\end{array}$ & (nsa) \\
\hline $\begin{array}{l}\text { Natureza da } \\
\text { organização }\end{array}$ & $\begin{array}{l}\text { Independente } \\
\text { dummy }\end{array}$ & Sociedade $=1 ;$ escritório $=0$ & \multirow{5}{*}{ Demográficas } & + \\
\hline $\begin{array}{l}\text { Tamanho da } \\
\text { organização }\end{array}$ & $\begin{array}{l}\text { Independente } \\
\text { numérica }\end{array}$ & Número de empregados & & + \\
\hline Local & $\begin{array}{l}\text { Independente } \\
\text { dummy }\end{array}$ & $\begin{array}{l}\text { Cidade do Rio de Janeiro = } 1 ; \\
\text { Fora do Rio }=0\end{array}$ & & + \\
\hline $\begin{array}{l}\text { Idade da } \\
\text { organização }\end{array}$ & $\begin{array}{l}\text { Independente } \\
\text { numérica }\end{array}$ & Anos desde a fundação & & $?$ \\
\hline Inovação & $\begin{array}{l}\text { Independente } \\
\text { dummy }\end{array}$ & $\begin{array}{l}\text { Houve alguma inovação }=1 ; \\
\text { não houve }=0\end{array}$ & & + \\
\hline
\end{tabular}




\section{repec}

Diversificação do Treinamento em Organizações Contábeis: Uma Análise Empírica Utilizando Modelos de Contagem

\begin{tabular}{|l|l|l|c|c|}
\hline $\begin{array}{l}\text { Leque de } \\
\text { Serviços }\end{array}$ & $\begin{array}{l}\text { Independente } \\
\text { numérica }\end{array}$ & $\begin{array}{l}\text { Soma das dummies para "servi- } \\
\text { ços oferecidos" }\end{array}$ & + \\
\cline { 1 - 2 } $\begin{array}{l}\text { Temas pesquisados } \\
\text { sobre mercado }\end{array}$ & $\begin{array}{l}\text { Independente } \\
\text { numérica }\end{array}$ & $\begin{array}{l}\text { Soma das dummies para "te- } \\
\text { mas pesquisados" }\end{array}$ & \multirow{2}{*}{$\begin{array}{l}\text { Produto / } \\
\text { Mercado }\end{array}$} & + \\
\cline { 1 - 3 } $\begin{array}{l}\text { Monitoramento da } \\
\text { concorrência }\end{array}$ & $\begin{array}{l}\text { Independente } \\
\text { numérica }\end{array}$ & $\begin{array}{l}\text { Soma das dummies para "for- } \\
\text { mas de monitoramento assina- } \\
\text { ladas" }\end{array}$ & & \multirow{2}{*}{} \\
\cline { 3 - 5 }
\end{tabular}

Fonte: Autores

A literatura internacional relata pesquisas em que diversas questões relacionadas a treinamento foram analisadas por intermédio da análise de regressão. Por exemplo, Reid e Harris (2002) analisaram os fatores determinantes do treinamento em pequenas e médias empresas na Irlanda do Norte; Altonji e Spletzer (1991) estudaram a associação entre treinamento e características do empregado e do trabalho; Westhead (1998) discutiu aspectos relacionados a treinamento formal patrocinado pelos empregadores; e Chiaburu e Tekleab (2005) investigaram os antecedentes pessoais e contextuais da eficácia de programas de treinamento.

\subsection{Limitações da pesquisa}

Devido ao processo de coleta postal, a amostra não foi aleatória. Apesar de todos os cuidados, a amostra efetiva final representou pouco mais de $16 \%$ da amostra originalmente escolhida. Inúmeros pesquisados não quiseram ou não puderam responder os questionários. A título de exemplo, por defeitos no cadastro, cinquenta questionários foram devolvidos como "destinatário não encontrado" e dois foram enviados a respondentes já falecidos. Possivelmente muitos não responderam, porque não estavam suficientemente motivados a fazê-lo.

Sendo o questionário autoadministrado e tendo sido enviado pelo correio, muitos foram devolvidos sem algumas respostas. O questionário enviado era relativamente extenso, já que se pretendia fazer um levantamento amplo e abrangente. Embora o tempo estimado para responder o questionário fosse de aproximadamente 40 minutos, muitos profissionais podem tê-lo julgado excessivo diante de suas ocupações e negócios.

Apesar de o questionário ter sido elaborado sob a preocupação de evitar erros de interpretação por parte dos respondentes, ainda assim a formulação final pode ter trazido alguma distorção devido a dificuldades de entendimento das questões por parte dos respondentes. Além disso, a sequência das perguntas e a ordem na apresentação das alternativas costumam interferir nas respostas.

Pode ter havido distorção, também, decorrente de cansaço, da pressa ou da falta de disposição dos entrevistados. Como o preenchimento ocorreu à distância, não foi possível detectar tais situações. Nesse tipo de instrumento de pesquisa, a pergunta fechada facilita a padronização de pontos de vistas, em detrimento das nuances e das especificidades. Pode-se, então, 
alcançar bom conhecimento dos problemas, mas nem sempre um diagnóstico mais amplo.

Há ainda que considerar, a título de limitação metodológica, o fato de que o questionário deixou de analisar aspectos importantes tais como os relacionados a treinamento interno e externo (cf. BUSHARDT; FRETWELL; CUMBEST, 1994), aos gastos com treinamento (cf. REID; HARRIS, 2002, ou VAN BUREN; KING, 2000), à educação continuada, aos critérios de seleção para receber treinamento, à questão da eficácia do treinamento (CHIABURU; TEKLEAB, 2005) ou à sua duração.

A despeito de não ter sido possível identificar estudos empíricos semelhantes no Brasil, já que a pesquisa do CFC (1996) restringiu-se a registrar resultados descritivos, há que reconhecer a limitação decorrente dos dados terem sido coletados em 2002, o que recomenda cautela na "utilização prática" dos resultados aqui obtidos. Um exemplo de retardo na análise de pesquisas empíricas pode ser encontrado em Tuijnman e Boudard (2001), em Fortin e Parent (2006) ou em Façanha e Resende (2010). Em geral, o atraso se deve ao custo ou à dificuldade de replicar pesquisas de campo de médio ou grande porte, especialmente se os respondentes estão "no mundo real", em oposição a "amostras de estudantes", ou quando há levantamento de dados primários originais, tal como ocorreu aqui.

\section{RESULTADOS}

Nesta seção são apresentados os resultados da pesquisa. Na primeira subseção estão os resultados de natureza mais descritiva. Na segunda, são analisados os resultados da estimação das equações de regressão.

\subsection{Perfis descritivos}

Das organizações analisadas (531), os escritórios representaram 39,4\% das respostas válidas e as sociedades, 60,6\%. Em termos de tamanho, de acordo com o número de empregados (GOETZ, Jr.; MORROW; McELROY, 1991, p. 162), as organizações foram divididas em três classes: pequenas $(93,6 \%)$, médias $(4,9 \%)$ e grandes $(1,5 \%)$. O número médio de empregados foi calculado em 5,93 e a mediana igual a 4. A maioria das respondentes (a moda) possui 2 empregados. A idade das organizações respondentes $(n=463)$ variou entre 1 e 56 anos (1947 a 2002), sendo a média de 16 anos, a mediana igual a 13. A maioria das respondentes (61,5\% das respostas válidas) fica localizada na cidade do Rio de Janeiro, enquanto as demais (38,5\%) estão distribuídas pelos demais municípios do Estado.

$\mathrm{Na}$ Tabela 1, são apresentadas informações acerca do papel do empregado na criação de novos serviços. Percebe-se que, nas organizações respondentes, informações oriundas dos empregados têm reduzida participação - cerca de $7 \%$ - não obstante o fato de que, normalmente, os colaboradores internos representam fonte importante para implementação de novos serviços. 
Tabela 1 - Origem da criação de novos serviços

\begin{tabular}{|l|l|}
\hline Origem & Respostas $(\mathrm{n}=517)$ \\
\hline Solicitação da clientela & $83(16,1 \%)$ \\
\hline Pesquisa de mercado & $75(14,5 \%)$ \\
\hline Legislação & $61(11,8 \%)$ \\
\hline Informação/sugestão de funcionário & $37(7,2 \%)$ \\
\hline Consultores & $12(2,3 \%)$ \\
\hline
\end{tabular}

Fonte: Autores

Thomé (2001, p. 32) levantou uma lista dos serviços prestados por empresas contábeis brasileiras, incluindo consultoria, escrituração contábil, escrituração fiscal, auditoria, perícia e assessoria. Nessa pesquisa também foram obtidas informações sobre o mix de serviços ofertados pelas organizações pesquisadas, que aparecem na Tabela 2. Dentre o leque de serviços ofertados aos clientes, poucas organizações oferecem serviços tais como planejamento fiscal, concentrando suas ofertas em serviços relacionados ao cumprimento de aspectos legais. Vale observar, no que se refere ao planejamento fiscal, que a oferta desse serviço pode ser bem aceita pelos clientes, dada a relevância da carga tributária sobre os negócios em geral.

\section{Tabela 2 - Mix dos serviços ofertados *}

\begin{tabular}{|l|c|}
\hline Espécie de serviço & Respostas \\
\hline Imposto de Renda Pessoa Jurídica & $523(98,9 \%)$ \\
\hline Folha de Pagamento & $517(97,7 \%)$ \\
\hline Admissão/Demissão de Pessoal & $516(97,4 \%)$ \\
\hline Escrituração Contábil & $515(97,4 \%)$ \\
\hline Escrituração Fiscal & $512(96,8 \%)$ \\
\hline Registro de Empregados & $512(96,8 \%)$ \\
\hline Imposto de Renda Pessoa Física & $504(95,3 \%)$ \\
\hline Constituição e alteração de empresas & $477(90,2 \%)$ \\
\hline Assessoria Contábil & $431(81,5 \%)$ \\
\hline Consultoria & $250(47,3 \%)$ \\
\hline Análise de Balanços & $244(46,1 \%)$ \\
\hline Planejamento Fiscal & $220(41,6 \%)$ \\
\hline Planejamento Contábil & $208(39,3 \%)$ \\
\hline Controle Patrimonial & $184(34,8 \%)$ \\
\hline
\end{tabular}




\begin{tabular}{|l|l|}
\hline Contabilidade de Custos & $157(29,7 \%)$ \\
\hline Avaliação de Empresas & $91(17,2 \%)$ \\
\hline Perícia & $69(13,0 \%)$ \\
\hline Auditoria Externa & $65(12,3 \%)$ \\
\hline
\end{tabular}

Fonte: Autores

(*) $n=529$, exceto item número $3: n=530$

Em outra questão, a organização respondente deveria indicar se oferecia ou não treinamento para seus funcionários ou gerentes. Do total de respondentes (531), 69,5\% afirmaram positivamente quanto a oferecer treinamento. Não obstante, nas respostas a uma posterior questão de verificação, somente $46,4 \%$ das organizações declararam oferecer treinamento como um tipo de suporte aos seus funcionários e gerentes. O tema dos treinamentos oferecidos pelas respondentes pode ser apreciado na Tabela 3. A partir dessas respostas, percebe-se uma convergência entre o tema de treinamento mais frequente - legislação, com 48,3\% - e o serviço mais ofertado - imposto de renda para pessoa jurídica.

$\mathrm{Na}$ Tabela 4, são apresentados alguns tipos de suporte oferecidos ao exercício profissional de empregados e gerentes. O fato de as organizações pesquisadas oferecerem, em sua maioria, um ambiente físico adequado, de delegarem poder para resolução de problemas e de realizarem treinamento configura resultado positivo e relevante. Por outro lado, é reduzido o percentual de organizações que oferecem suporte sob a forma de laptops e softwares, que alcançou quase $24 \%$. Talvez se possa dizer, ademais, que o percentual ficou aquém do esperado, na medida em que esse tipo de ferramenta é importante para profissionais contábeis que necessitam acessar banco de dados e gerenciar informações contábeis e que exercem atividades de auditoria e consultoria, visto que tais recursos proporcionam mobilidade e maior eficiência na resolução de problemas.

\section{Tabela 3 -Temas dos treinamentos}

\begin{tabular}{|l|c|}
\hline Área / Assunto & Respostas $(\mathrm{n}=528)$ \\
\hline Legislação & $255(48,3 \%)$ \\
\hline Informática aplicada à Contabilidade & $234(44,3 \%)$ \\
\hline Capacitação em contabilidade & $216(40,9 \%)$ \\
\hline Atendimento a clientes & $135(25,6 \%)$ \\
\hline Motivação & $100(18,9 \%)$ \\
\hline Pacotes financeiros & $6(1,1 \%)$ \\
\hline Vendas & $4(0,8 \%)$ \\
\hline
\end{tabular}

Fonte: Autores 
Tabela 4 - Suporte oferecido a funcionários e gerentes

\begin{tabular}{|l|c|}
\hline Tipo de suporte & $\begin{array}{c}\text { Respostas ( } \mathrm{n}= \\
521)\end{array}$ \\
\hline Ambiente físico adequado & $375(72,0 \%)$ \\
\hline Autonomia para resolução de problemas & $280(53,7 \%)$ \\
\hline Treinamento & $242(46,4 \%)$ \\
\hline Informática (laptops, softwares, etc.) & $124(23,8 \%)$ \\
\hline Prêmios (dinheiro, viagens, etc.) & $81(15,5 \%)$ \\
\hline Manuais padronizados para lidar com clientes & $76(14,6 \%)$ \\
\hline Telefones / faxes exclusivos & $68(13,1 \%)$ \\
\hline Brindes & $50(9,6 \%)$ \\
\hline Material promocional & $36(6,9 \%)$ \\
\hline Cadastro para prospecção de clientes & $18(3,5 \%)$ \\
\hline Reuniões de vendas & $16(3,1 \%)$ \\
\hline
\end{tabular}

Fonte: Autores

Resumindo, apesar de a maioria das respondentes ter sido classificada como organizações contábeis de pequeno porte, são relevantes os percentuais daquelas que dispõem de ambiente físico adequado, que delegam poder e que proporcionam atividades de treinamento a seus colaboradores. Não obstante ser essa uma percepção da organização respondente, e não necessariamente do empregado, espera-se que essa atitude deva traduzir-se em satisfação no trabalho, em retenção das equipes e em mais motivação para que os funcionários atuem na consecução dos objetivos da organização e da satisfação do cliente.

Uma pergunta do questionário buscou verificar se as organizações analisadas têm procurado conhecer temas atuais e relevantes para a continuidade do negócio, tais como: satisfação do cliente; tamanho do mercado; análise da concorrência; pesquisa de mídia; análise de vendas e parcelas do mercado; e diferenciação de serviços. Foi constatado que, dentre 518 respondentes, 176 (34,0\%) analisaram um tema, 181 (34,9\%), dois temas e 94 (18,1\%), três temas, perfazendo um total de 451 (87\%) de empresas que procuraram conhecer as condições de seus mercados.

Os números da Tabela 5 mostram informações acerca do papel do empregado no monitoramento da concorrência. Pelo que se vê, o funcionário tem papel importante semelhante ao das pesquisas de mercado, ambos bem menos relevantes do que o papel desempenhado pelos clientes. 
Tabela 5 - Monitoramento da concorrência

\begin{tabular}{|l|c|}
\hline Instrumento & Respostas $(\mathrm{n}=519)$ \\
\hline Informações dos clientes & $346(66,7 \%)$ \\
\hline Informações dos empregados & $129(24,9 \%)$ \\
\hline Pesquisas de mercado & $105(20,2 \%)$ \\
\hline Imprensa & $74(14,3)$ \\
\hline Consultoria & $15(2,9 \%)$ \\
\hline
\end{tabular}

Fonte: Autores

\subsection{Teste das hipóteses}

Nesta subseção, duas tabelas foram elaboradas para exibir os resultados dos testes de hipóteses, que se apoiam no sinal e na significância estatística dos coeficientes das equações estimadas. Foram utilizadas duas abordagens alternativas para estimação dos coeficientes - Modelo de Poisson (Tabela 3.6) e Modelo da Binomial Negativa (Tabela 3.7). Essas duas especificações se justificam pela natureza da variável dependente, conforme explicado na seção anterior

Tabela 6 - Resultados* da Regressão Múltipla - Máxima Verossimilhança**

\begin{tabular}{|l|c|c|c|}
\hline Variáveis & Coeficientes & Erro Padrão & Signif. \\
\hline Constante & $-0,6022$ & 0,1888 & 0,001 \\
\hline NUM. EMPREGADOS & 0,0077 & 0,0029 & 0,008 \\
\hline IDADE EMPRESA & $-0,0012$ & 0,0030 & 0,680 \\
\hline INOVAÇÃO & 0,1973 & 0,0772 & 0,011 \\
\hline LEQUE SERVIÇOS & 0,0713 & 0,0148 & 0,000 \\
\hline LOCAL & 0,0570 & 0,0889 & 0,522 \\
\hline MONITORA & 0,0776 & 0,0383 & 0,043 \\
\hline NATUREZA & $-0,1492$ & 0,0989 & 0,131 \\
\hline TEMAS ANALISADOS & 0,1092 & 0,0387 & 0,005 \\
\hline
\end{tabular}

$\left(^{*}\right) n=433 ;$ Adj. $R^{2}=0,2018 ; \quad L R=131,412 ; p<0,1 \%$

$\left({ }^{* *}\right)$ Modelo de Poisson; teste de superdispersão significativo a $0,1 \%$; erros-padrão calculados pela fórmula de White. 
Tabela 7 - Resultados* da Regressão Múltipla - Máxima Verossimilhança **

\begin{tabular}{|l|c|c|c|}
\hline Variáveis & Coeficientes & Erro Padrão & Signif. \\
\hline Constante & $-0,6133$ & 0,1923 & 0,0014 \\
\hline NUM. EMPREGADOS & 0,0082 & 0,0032 & 0,0094 \\
\hline IDADE EMPRESA & $-0,0011$ & 0,0031 & 0,7187 \\
\hline INOVAÇÃO & 0,2034 & 0,0778 & 0,0090 \\
\hline LEQUE SERVIÇOS & 0,0708 & 0,0152 & 0,0000 \\
\hline LOCAL & 0,0544 & 0,0904 & 0,5473 \\
\hline MONITORA & 0,0791 & 0,0392 & 0,0438 \\
\hline NATUREZA & $-0,1479$ & 0,1006 & 0,1414 \\
\hline TEMAS ANALISADOS & 0,1122 & 0,0393 & 0,0043 \\
\hline
\end{tabular}

$\left.{ }^{*}\right) n=433 ;$ Adj. $R^{2}=0,1978 ; \quad L R=134,9344 ; p<0,001 \%$

$\left(^{* *}\right)$ Modelo Binomial Negativo; parâmetro de forma significativo a $0,1 \%$.

O primeiro resultado que vale a pena destacar se refere ao fato de que as mesmas variáveis são sempre significativas (ou não), independentemente do método de estimação. Esse resultado pode ser entendido como uma "validação cruzada" da importância das variáveis significativas. Em segundo lugar, os sinais dos coeficientes das variáveis correspondem à expectativa, permitindo inferir que quanto mais serviços forem ofertados (incluindo os novos serviços), maior será o número de empregados e mais treinamento ocorrerá. Em terceiro lugar, a significância dos testes de nulidade simultânea dos coeficientes (teste LR) é muito alta, indicando que as equações têm poder explicativo. Os valores de R2 não são altos, como geralmente ocorre em cross sections.

Finalmente, quanto às variáveis explicativas, vale observar a elevada significância da variável "leque", que mede a diversificação dos serviços oferecidos, indicando que as empresas amostradas procuram fazer com que a diversificação de sua oferta esteja associada à diversificação do treinamento oferecido.

Além disso, nas duas equações estimadas verificou-se que a variável "tamanho" (medida pelo número de empregados) desponta como significativa, concluindo-se que se trata de uma variável explicativa robusta e importante. Esse resultado é "natural" e esperado no sentido de que a população de empregados representa, potencialmente, a demanda por treinamento em uma empresa. Vale lembrar que o fato de o tamanho poder ser (como que ambiguamente) entendido no sentido de "demanda potencial" é típico em contextos - tais como esse em que se trabalha aqui - de estimação de uma "forma reduzida". Nesse caso, o modelo estimado mostra apenas a solução uniequacional de um sistema de equações de 
oferta e demanda por treinamento, expressa em função de variáveis pré-determinadas (ver, por exemplo, PINDYCK; RUBINFELD, 2004)

\section{CONCLUSÕES}

Ao longo do texto discutiram-se aspectos relacionados à gestão de pessoas em organizações contábeis, situando-a em um contexto de melhoria do desempenho pessoal e profissional do contador profissional, em especial no que se refere à oferta de atividades de treinamento. Ao proceder à revisão da literatura, foi observado como é reduzido o número de pesquisas, recentes ou não, que abordem especificamente questões relacionadas ao treinamento para o profissional de Contabilidade.

Os resultados obtidos na presente pesquisa permitem concluir pela existência de associações entre atividades de treinamento e algumas características das organizações estudadas, conforme postulou a hipótese de pesquisa. Na literatura nacional resenhada não foi possível descobrir nenhuma pesquisa semelhante.

Levando em consideração apenas as frequências relativas das respostas às perguntas do questionário, podem-se destacar dois pontos. Primeiro, tendo em mente a importância naturalmente atribuída a questões tributárias, existe convergência entre o tema em que há treinamento mais frequente - legislação, com $48,3 \%$ - e o serviço mais ofertado, o imposto de renda da pessoa jurídica; essa descoberta pode ter consequências para várias instituições que atuam na área educacional, aí incluídas as universidades. Segundo, é de certa forma surpreendente constatar o reduzido (cerca de $24 \%$ ) percentual de organizações que oferecem suporte sob a forma de laptops e softwares, visto que esse tipo de ferramenta é importante para profissionais contábeis, sempre necessitando acessar banco de dados e gerenciar informações contábeis, já que tais utilidades proporcionam mobilidade e maior eficiência na resolução de problemas. Essa descoberta, apesar de datada, pode ter consequências interessantes para fabricantes de equipamentos e fornecedores de softwares em termos de exploração de oportunidades comerciais ou de parcerias.

Os testes da hipótese revelaram a existência de associações diretas e significativas entre algumas características organizacionais e a diversidade nas atividades de treinamento. A evidência empírica obtida indica que a idade - que pode ser vista como uma proxy para "experiência" (FORTIN, 2006, p. 15) - e a localização das organizações contábeis não têm influência significativa sobre as atividades de treinamento. Esse resultado é compreensível quando se recorda que, como a empresa contábil se apoia nos conhecimentos e iniciativas dos profissionais envolvidos, a atualização dos conhecimentos não precisa depender de "antiguidade" ou localização.

Verificou-se ainda que o "leque de serviços" e o "tamanho" foram variáveis importantes e significativas nas duas especificações examinadas, confirmando sua influência sobre 
a diversidade da oferta de treinamento. A propósito, na literatura aqui resenhada, nacional ou não, não foi possível identificar a utilização da variável "leque de serviços", apesar de sua relevância, tal como apontada na teoria da diversificação em organizações de serviços (ver, por exemplo, ATAMER; CALORI, 1993).

A reação positiva e significativa da diversificação do treinamento a condições de mercado e a requisitos operacionais (decorrentes da diversidade dos serviços oferecidos) constitui uma contribuição específica deste trabalho ao entendimento da gestão de pessoas em organizações contábeis. Esses resultados interessam não somente à programação de atividades internas nessas empresas, mas também a organizações que forneçam tais programas, tanto privadas quanto públicas, incluindo conselhos profissionais.

Finalmente, é inegável que diferentes atividades de treinamento podem envolver tipos muito distintos entre si (ver Tabela 3), por exemplo, quanto à complexidade, à duração ou à eficácia para a empresa contábil. Assim sendo, uma área para pesquisa futura inclui um esforço mais pormenorizado de caracterização da diversificação da oferta de treinamento. Com efeito, a simples mensuração dessa diversificação em termos do "total de tipos de treinamento" não revela importantes características relacionadas a cada tipo. Essa linha de investigação, contudo, ultrapassa o escopo do presente trabalho.

\section{REFERÊNCIAS}

ALMEIDA, M. C. Auditoria: um curso moderno e completo. 6. ed. São Paulo: Atlas, 2003.

ALTONJI, J. G.; SPLETZER, J. R. Worker characteristics, job characteristics, and the receipt of on-the-job training. Industrial and Labor Relations Review, v. 45, n. 1, p. 58-79, 1991.

ARCHERD, W. R. Training of Accounting Staff. NACA Bulletin, v. 31, n. 6, p.776-777,1951.

ATAMER, T.; CALORI, R. Diagnostic et Décisions Stratégiques. Paris: Dunod Entreprises, 1993.

BATESON, J. E. G.; HOFFMAN, K. D. Marketing de Serviços. 4. ed. Porto Alegre: Bookman, 2001.

BECKER, G. Human Capital. Chicago: University of Chicago Press, 1964.

BLACK, D. A.; BRETT, J. N.; WANG, Z. On-the-Job Training, Establishment Size and Firm Size: evidence for economies of scale in the production of human capital, Southern Economic Journal, v. 66, n. 1, p. 82-100, 1999. 
BUSHARDT, S. C.; FRETWELL, C.; CUMBEST, P. By. Continuous Improvement through Employee Training: a Case Example from the Financial Services Industry. The Learning Organization, v. 1, n. 1, p. 11-16, 1994.

CAMERON, A. C.; TRIVEDI, P. K., Regression Analysis of Count Data, Cambridge: Cambridge University Press, 1998.

CHIABURU, D. S.; TEKLEAB, A. Individual and contextual influences on multiple dimensions of training effectiveness, Journal of European Industrial Training, v. 29, no. 8, p. 604-626, 2005.

CONSELHO FEDERAL DE CONTABILIDADE - CFC. Resolução CFC no. 868/99. Brasília: DOU 24/12/1999.

Perfil do Contabilista Brasileiro. Brasília: CFC, 1996.

DIXON, W. J.; MASSEY Jr., F. Introduction to Statistical Analysis. International Student Edition. 3. ed. Tokyo: McGraw-Hill / Kogakusha, 1969.

FAÇANHA, L. O.; RESENDE, M. Determinants of hierarchical structure in industrial firms: an empirical study. Economics of Governance, v. 11, n. 3, p. 295-308, 2010.

FORTIN, N.; PARENT, D. The Training Divide: a Canada-US Comparison of Employee Training, Working Paper 2006 - B - 09, HRSDC, Government of Canada, 2006.

GOETZ Jr., J. F.; MORROW, P. C.; McELROY, J. C. The effect of accounting firm size and member rank on professionalism. Accounting, Organizations and Society, v.16, n. 2, p. 159-165, 1991.

HENDRY, C.; JONES, A.; ARTHUR, M.; PETTIGREW A. Human Resource Development in Small to Medium Sized Enterprises, Research Paper no. 88. London: Employment Department, 1991.

HOLTMANN, A; IDSON, T. L. Employer Size and On-the-Job Training Decisions. Southern Economic Journal, v. 58, n. 2, p. 339-355, 1991.

KEEP, E.; MAYHEW, K. Evaluating the assumptions that underlie training policy, in 
BOOTH, A.; SNOWER, D. (Orgs.). Acquiring Skills: Market Failure, their Symptoms, and Policy Responses. Cambridge: Cambridge University Press, p. 305-334, 1996.

KURLANDER, C. E.; BATTISTA, G. L. Progressive Organizations Provide for Accounting Training. NAA Bulletin, v. 41, n. 12, p. 81-89, 1960.

LOVELOCK, C.; WRIGHT, L. Serviços: marketing e gestão. São Paulo: Saraiva, 2004.

LUMAN, J. A. Importance of Accounting Training. The Journal of Accountancy, v. 11, n. 6 , p. 405-413, 1911.

MYTZEK-ZUHLKE, R; NITSCHE, N. Institutions and Costs: Determinants of Firm Financed Training Activities in Four European Country, Working Paper, Berlin: Social Science Research Center, 2006.

PINDYCK, R. S.; RUBINFELD, D. L. Econometria. Rio de Janeiro: Campus, 2004.

PITTS, C. L. Better Training of Accounting Trainees. NAA Bulletin, v. 43, n.c 11, p. 90, 1962.

REID, R. S.; HARRIS, R. I. D. The determinants of training in SMEs in Northern Ireland. Education \& Training, vol. 44, n.8/9, p. 443-450, 2002.

SHIELDS, M. Changes in the Determinants of Employer-Funded Training for Full-Time Employees in Britain, 1984-1994. Oxford Bulletin of Economics and Statistics, v. 60, n. 2, p. 189-214, 1998.

SMITH, A.; ROBERTS, P.; NOBLE, C.; HAYTON, G.; THORNE, E. Industry Training: the Factors that Affect Demand. Discussion Paper, Brisbane: Australian National Training Authority, 1995.

SWEENEY, J. T.; SUMMERS, S. L. The effect of the busy season workload on Public Accountants' job burnout. Behavioral Research in Accounting, v.14, p. 223-245, 2002.

THOMÉ, I. Empresas de Serviços Contábeis: estrutura e funcionamento. São Paulo: Atlas, 2001.

TUIJNMAN, A.; BOUCHARD, E. Adult Education Participation in North America: International Perspectives. Working Paper. Ottawa: Statistics Canada, 2001. 
TURCOTTE, J.; LEONARD, A.; MONTMARQUETTE, C. New evidence on the Determinants of Training in Canadian Business Locations, Occasional Paper, Ottawa: Statistics Canada, 2003.

Van BUREN, M. E.; KING, S. B. ASTD's annual accounting of worldwide patterns in employer provided training, Training \& Development, p. 1-24, 2000.

WESTHEAD, P. Factors associated with the provision of job-related formal training by employers. International Journal of Entrepreneurial Behaviour \& Research, v. 4, n. 3, p. 187-216, 1998.

ZEITHAML, V. A.; BITNER, M. J. Marketing de Serviços: a empresa com foco no cliente. 2. ed. Porto Alegre: Bookman, 2003. 